\title{
Ultrafast Electron/Energy Transfer and Intersystem Crossing Mechanisms in BODIPY-Porphyrin Compounds
}

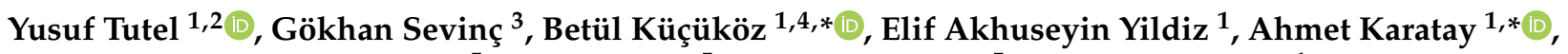 \\ Fatih Mehmet Dumanoğulları ${ }^{5}$, Halil Yılmaz ${ }^{5}$, Mustafa Hayvali ${ }^{5}$ and Ayhan Elmali ${ }^{1}$ \\ 1 Department of Engineering Physics, Faculty of Engineering, Ankara University, 06100 Ankara, Turkey; \\ ytutel@metu.edu.tr (Y.T.); eakhuseyin@ankara.edu.tr (E.A.Y.); elmali@eng.ankara.edu.tr (A.E.) \\ 2 Department of Metallurgical and Materials Engineering, Middle East Technical University, \\ 06800 Ankara, Turkey \\ 3 Department of Chemistry, Science and Literature Faculty, Bilecik Şeyh Edebali University, \\ 11230 Bilecik, Turkey; gokhan.sevinc@bilecik.edu.tr \\ 4 Department of the Physics, Chalmers University of Technology, 41296 Gothenburg, Sweden \\ 5 Department of Chemistry, Faculty of Science, Ankara University, 06100 Ankara, Turkey; \\ dumanogullari@gmail.com (F.M.D.); hllylmz_84@hotmail.com (H.Y.); hayvali@science.ankara.edu.tr (M.H.) \\ * Correspondence: kucukoz@chalmers.se (B.K.); akaratay@eng.ankara.edu.tr (A.K.)
}

Citation: Tutel, Y.; Sevinç, G.; Küçüköz, B.; Akhuseyin Yildiz, E.; Karatay, A.; Dumanoğulları, F.M. Yılmaz, H.; Hayvali, M.; Elmali, A. Ultrafast Electron/Energy Transfer and Intersystem Crossing

Mechanisms in BODIPY-Porphyrin Compounds. Processes 2021, 9, 312. https://doi.org/10.3390/pr9020312

Academic Editor: Jian Liu

Received: 29 December 2020

Accepted: 5 February 2021

Published: 8 February 2021

Publisher's Note: MDPI stays neutral with regard to jurisdictional claims in published maps and institutional affiliations.

Copyright: (c) 2021 by the authors. Licensee MDPI, Basel, Switzerland. This article is an open access article distributed under the terms and conditions of the Creative Commons Attribution (CC BY) license (https:// creativecommons.org/licenses/by/ $4.0 /)$.

\begin{abstract}
Meso-substituted borondipyrromethene (BODIPY)-porphyrin compounds that include free base porphyrin with two different numbers of BODIPY groups (BDP-TTP and 3BDP-TTP) were designed and synthesized to analyze intramolecular energy transfer mechanisms of meso-substituted BODIPY-porphyrin dyads and the effect of the different numbers of BODIPY groups connected to free-base porphyrin on the energy transfer mechanism. Absorption spectra of BODIPY-porphyrin conjugates showed wide absorption features in the visible region, and that is highly valuable to increase light-harvesting efficiency. Fluorescence spectra of the studied compounds proved that BODIPY emission intensity decreased upon the photoexcitation of the BODIPY core, due to the energy transfer from BODIPY unit to porphyrin. In addition, ultrafast pump-probe spectroscopy measurements indicated that the energy transfer of the 3BDP-TTP compound (about $3 \mathrm{ps}$ ) is faster than the BDP-TTP compound (about 22 ps). Since the BODIPY core directly binds to the porphyrin unit, rapid energy transfer was seen for both compounds. Thus, the energy transfer rate increased with an increasing number of BODIPY moiety connected to free-base porphyrin.
\end{abstract}

Keywords: borondipyrromethene; porphyrin; Förster resonance energy transfer; ultrafast pump-probe spectroscopy

\section{Introduction}

Borondipyrromethene (BODIPY) chromophores have attracted great interest, due to some favorable features such as sharp absorption and emission bands (500 $\mathrm{nm})$, high fluorescence quantum yields and molar absorption coefficients, outstanding chemical photostability, and long excited state lifetimes[1-5]. They also have good solubility in organic solvents [3,5,6] and fluorescent properties modifiable with structural substations [2]. Furthermore, it is known that they are exceedingly stable dyes because they are relatively insensitive to the $\mathrm{pH}$ of the media [7]. It is a big advantage for BODIPY dyes to have been used in wide application areas such as biological labeling [8], luminescent devices [9], chemical sensors [10-14], light-harvesting arrays [15-18], supramolecular fluorescent gels [19], and triplet photosensitizers [20]. Double chromophore systems have been studied recently to investigate photoinduced intermolecular electron and/or energy transfer process such as some BODIPY-chromophores which are conjugated to porphyrin [15,21-23], pyrene [2,24], rhodamine [25], anthracene [26,27], carbazole [28], and BODIPY [29-34].

On the other hand, porphyrins, a group of tetrapyrrolic aromatic macrocycles, demonstrate a strong Soret band in the $400-800 \mathrm{~nm}$ region and four intense Q-bands, while 
metalloporphyrins display a dominant Soret band and one or two Q-bands in the same spectral region. They form complex structures with metal ions [35-37] and nonmetals [38], they are also the most widely investigated chromophores, due to their importance in biochemical processes [39-41]. Besides, due to their photosensitizing properties, porphyrins have been widely used as light-harvesting antennas to capture and transfer light to the other porphyrin units [42-46]. Since porphyrins do not absorb strongly in the range of 450 and $550 \mathrm{~nm}$ wavelength, they have a limited usage area in solar cell applications. In an attempt to enhance the light-harvesting capability and absorption features of porphyrins in that region, BODIPY chromophore, with its strong absorbing properties, can be attached to the porphyrin unit. BODIPY absorbs light strongly around $500 \mathrm{~nm}$, while porphyrin absorbs strongly in the $420-450 \mathrm{~nm}$ region and weakly in the $500-700 \mathrm{~nm}$ region. Therefore, BODIPY and porphyrin have complementary light-absorbing features. Thus, BODIPYporphyrin conjugates result in a wide range of absorption in the visible region, either covalently or non-covalently bonded, which is highly desirable to increase light-gathering efficiency across the solar spectrum. Generally, such molecular structures demonstrate efficient and rapid energy transfer from BODIPY to the porphyrin unit in accordance with the type of conjugation and the position of BODIPY. Increasing or decreasing the energy transfer rate is important for many applications and modifying this property in organic molecules provides great advantages [47-49].

By combining different numbers of BODIPY moiety to free-base porphyrin, it is possible to improve and modify some optical properties of porphyrin. We herein examine the optical properties and the energy transfer mechanism of the two porphyrin-based compounds with different numbers of BODIPY groups on the electronic energy levels of the porphyrin ring. The experimental results of fluorescence, excitation, and ultrafast pump-probe spectroscopy measurements prove the energy transfer from the BODIPY unit to porphyrin.

\section{Experiment}

\subsection{Materials and Equipment}

Compound formyl-BODIPY was synthesized from the literature procedure [41]. All other solvents and reagents were purchased from Sigma Aldrich Co. and used as received. Reactions were monitored by TLC (with $\mathrm{F}_{254}$ indicator) on pre-coated silica gel plates revealed by exposure to a $\mathrm{UV}_{254}$ lamp. Barnstead Electrothermal 9100 platform was used for the melting point determinations. Mass spectra data were acquired in an Agilent Technologies 6224 (LC/MS) and Waters 2695 Alliance Micromass ZQ Mass spectrometer. NMR were measured by VARIAN Mercury instrument in deuterium chloroform $(400 \mathrm{MHz}$ for ${ }^{1} \mathrm{H}$ and $100 \mathrm{MHz}$ for ${ }^{13} \mathrm{C}$ ). Chemical shifts are reported in ppm versus internal $\mathrm{Me}_{4} \mathrm{Si}$ as a standard.

\subsection{Synthesis}

Synthesis of Compounds 5-\{4-[8-(2,6-Diethyl-4,4-Difluoro-1,3,5,7-Tetramethyl-4-Bora-3a,4aDiaza-S-Indacene)]-Phenyl\}-10,15,20-Tris(4-Methylphenyl)Porphyrin (Bdp-Ttp) and 5,10,15Tris\{4-[8-(2,6-Diethyl-4,4-Difluoro-1,3,5,7-Tetramethyl-4-Bora-3a,4a-Diaza-S-Indacene)]-Phenyl\}20-(4-Methylphenyl)Porphyrin(3BDP-TTP).

1H-pyrrole $(1.08 \mathrm{mmol}, 75 \mu \mathrm{L})$, 4-methylbenzaldehyde $(60 \mu \mathrm{L}, 0.49 \mathrm{mmol})$ and formylBODIPY (200 mg, $0.49 \mathrm{mmol})$ were dissolved in absolute $\mathrm{CH}_{2} \mathrm{Cl}_{2}(50 \mathrm{~mL})$. The reaction mixture was purged with argon bubbles for $5 \mathrm{~min}$. As a catalyst, one drop of $\mathrm{BF}_{3} \cdot \mathrm{Et}_{2} \mathrm{O}$ was added, and the solution was stirred for $1 \mathrm{~h}$. At the end of this time, TLC analysis showed complete consumption of the aldehyde. Then, tetrachloro-p-benzoquinone (p-chloranil, $300 \mathrm{mg}, 1.23 \mathrm{mmol}$ ) was added. Stirring was continued for another hour, then the crude product was washed with water, dried over $\mathrm{Na}_{2} \mathrm{SO}_{4}$, filtered, and evaporated to dryness. Column chromatography was conducted with benzene:chloroform elution $(1: 1 ; v / v)$ to isolate BDP-TTP and 3BDP-TTP, Scheme 1. In addition to isolated compounds, we also observed some unidentified compounds in trace amounts that could be porphyrin products 
with two and four BODIPY units from the mixture of the final products. According to thin layer chromatography, the mixture is believed to consist of a number of compounds from one to four meso-BODIPY substituted porphyrins. Yield: $33 \mathrm{mg}(7 \%)$ for the compound 3BDP-TTP, $\mathrm{mp}>300^{\circ} \mathrm{C}$ and yield: $83 \mathrm{mg}(11 \%)$ for the compound BDP-TTP, $\mathrm{mp}>300{ }^{\circ} \mathrm{C}$. BDP-TTP; ${ }^{1} \mathrm{H}-\mathrm{NMR}\left(400 \mathrm{MHz}, \mathrm{CDCl}_{3}\right): \delta[\mathrm{ppm}]: 8.92-8.84(\mathrm{~m}, 8 \mathrm{H}), 8.35(\mathrm{~d}, J=8.4 \mathrm{~Hz}$, $2 \mathrm{H}), 8.10(\mathrm{~d}, J=7.6 \mathrm{~Hz}, 6 \mathrm{H}), 7.70(\mathrm{~d}, J=8.0 \mathrm{~Hz}, 2 \mathrm{H}), 7.56(\mathrm{~d}, J=8.0 \mathrm{~Hz}, 6 \mathrm{H}), 2.71(\mathrm{~s}$, 9H), $2.64(\mathrm{~s}, 6 \mathrm{H}), 2.45(\mathrm{q}, J=7.5 \mathrm{~Hz}, 4 \mathrm{H}), 1.84(\mathrm{~s}, 6 \mathrm{H}), 1.11(\mathrm{t}, J=7.6 \mathrm{~Hz}, 6 \mathrm{H}),-2.76(\mathrm{~s}$, 1H). ${ }^{13} \mathrm{C}-\mathrm{NMR}\left(100 \mathrm{MHz}, \mathrm{CDCI}_{3}\right) \delta: 154.2(\mathrm{C}=\mathrm{N}), 139.0-127.0\left(\mathrm{C}=\mathrm{C}\right.$ phenyl), $143.2\left(\mathrm{C}_{\alpha}\right)$, $131.2\left(\mathrm{C}_{\beta}\right), 120.7\left(\mathrm{C}_{\mathrm{meso1}}\right), 118.8$ (Cmeso2), 21.8, 17.5, 15.0, 12.8, 12.4. HRMS (TOF-ESI): Calcd. for as $\left[\mathrm{C}_{64} \mathrm{H}_{57} \mathrm{BF}_{2} \mathrm{~N}_{6}\right] \mathrm{m} / \mathrm{z}$ : 958.47058 ; found, $959.47618[\mathrm{M}+\mathrm{H}]^{+},(1.75 \mathrm{ppm})$. 3BDPTTP; ${ }^{1} \mathrm{H}-\mathrm{NMR}\left(400 \mathrm{MHz}, \mathrm{CDCl}_{3}\right): \delta$ [ppm]: 8.98-8.82 (m, 8H), 8.40-8.37 (m, 6H), $8.12(\mathrm{~d}$, $J=7.6 \mathrm{~Hz}, 2 \mathrm{H}), 7.76-7.73(\mathrm{~m}, 6 \mathrm{H}), 7.58(\mathrm{~d}, J=7.6 \mathrm{~Hz}, 2 \mathrm{H}), 2.72(\mathrm{~s}, 3 \mathrm{H}), 2.65(\mathrm{~s}, 18 \mathrm{H}), 2.42(\mathrm{~d}$, $J=7.6 \mathrm{~Hz}, 12 \mathrm{H}), 1.90-1.85(\mathrm{~m}, 18 \mathrm{H}), 1.15-1.09(\mathrm{~m}, 18 \mathrm{H}),-2.71(\mathrm{~s}, 1 \mathrm{H}) .{ }^{13} \mathrm{C}-\mathrm{NMR}(100 \mathrm{MHz}$, $\left.\mathrm{CDCI}_{3}\right)$ 8: $154.4(\mathrm{C}=\mathrm{N}), 140.0-127.1(\mathrm{C}=\mathrm{C}$ phenyl $), 142.9\left(\mathrm{C}_{\alpha}\right), 131.2\left(\mathrm{C}_{\beta}\right), 119.6\left(\mathrm{C}_{\text {meso }}\right)$, 17.5, 15.0, 12.9, 12.5, 12.4. ES/MS calculated as $\left[\mathrm{C}_{96} \mathrm{H}_{95} \mathrm{~B}_{3} \mathrm{~F}_{6} \mathrm{~N}_{10}\right] \mathrm{m} / \mathrm{z}: 1534.79246$; found, $1535.8119[\mathrm{M}+\mathrm{H}]^{+},(7.92 \mathrm{ppm})$.
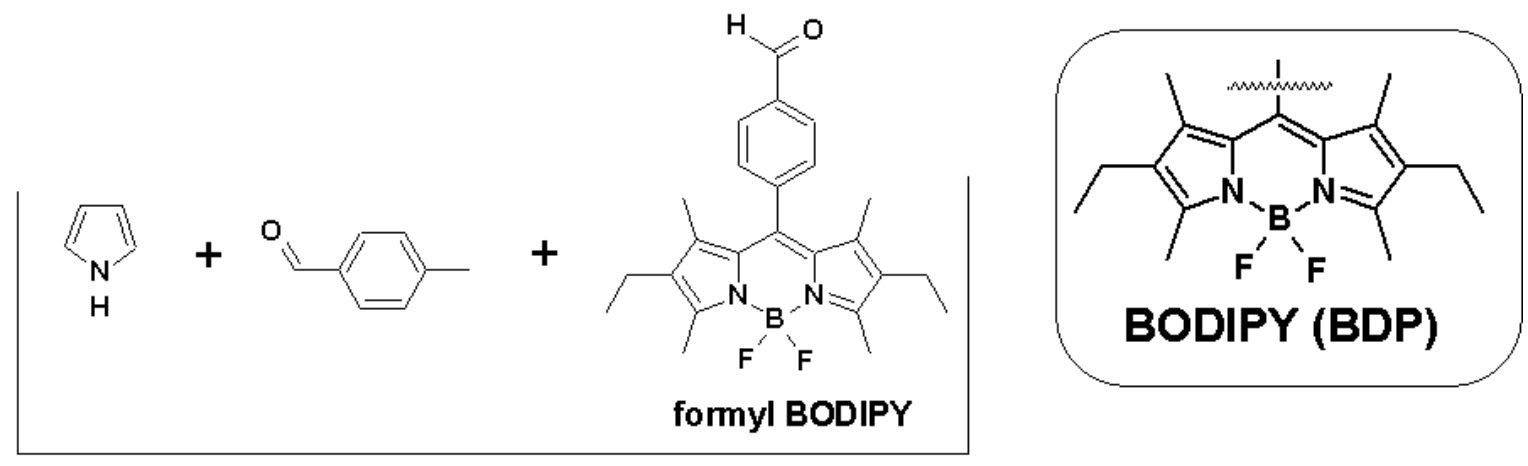

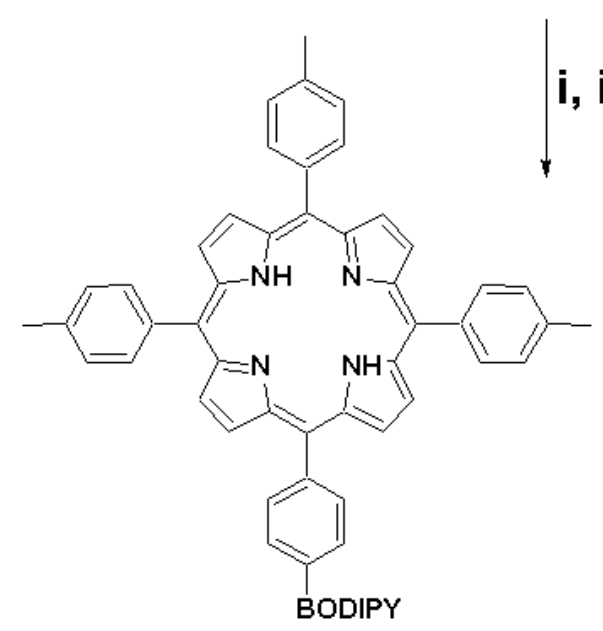

BDP-TTP

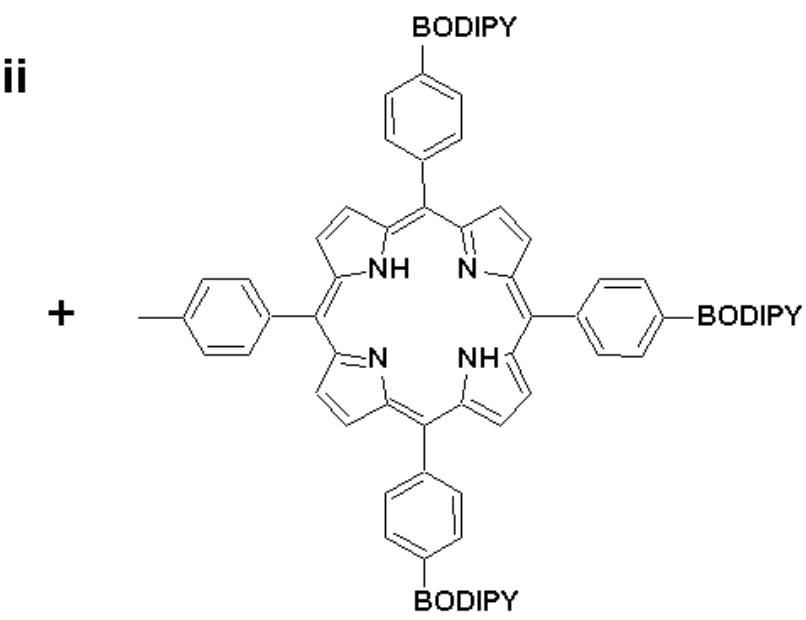

3BDP-TTP

Scheme 1. The synthesis of porphyrin-borondipyrromethene (BODIPY) sensitizers BDP-TTP and 3BDP-TTP (i acid catalyst $\mathrm{BF}_{3}$. $\mathrm{Et}_{2} \mathrm{O}, \mathrm{CH}_{2} \mathrm{Cl}_{2}, 1 \mathrm{~h}$, rt ii) $p$-Chloranil, $1 \mathrm{~h}$, rt.

\subsection{Optical Measurement}

The UV-Vis absorption and fluorescence spectra of the BODIPY-porphyrin compounds were measured with Shimadzu UV-1800 and Perkin Elmer model LS 55 spectrophotometers, respectively.

Ultrafast pump-probe spectroscopy measurements were carried out using Ti: Sapphire laser amplifier-optical parametric amplifier and a commercial pump-probe experimental setup (Spectra-Physics, Spitfire Pro XP, TOPAS, Helios). The pump wavelength was chosen 
as $524 \mathrm{~nm}$ and $400 \mathrm{~nm}$ to excite the singlet state of BODIPY and porphyrin, respectively, in the pump-probe experimental setup.

\section{Results and Discussion}

\subsection{Steady-State Absorption and Fluorescence Measurements}

Figure 1 depicts the linear absorption spectra of BODIPY-porphyrin compounds (BDP-TTP and 3BDP-TTP) in THF solution. The dominant Soret bands of BDP-TTP and 3BDP-TTP are localized at 416 and $419 \mathrm{~nm}$, respectively. In addition to that, weaker $Q$ bands in the 500-700 $\mathrm{nm}$ region were observed for both compounds $[5,41,50,51]$. The absorption peak at $524 \mathrm{~nm}$ is attributed to the lowest energy transitions $\left(\mathrm{S}_{0}-\mathrm{S}_{1}\right)$ of the BODIPY unit, while the strong absorption around $420 \mathrm{~nm}$ and weaker $Q$ bands come from the free-base porphyrin. The $\mathrm{Q}$ bands correspond to the transition from $\mathrm{S}_{0}$ to $\mathrm{S}_{1}$ of porphyrin moiety. As seen in Figure 1, the intensity of the absorption signal at $524 \mathrm{~nm}$ increases with an increasing number of BODIPY units, as is expected.

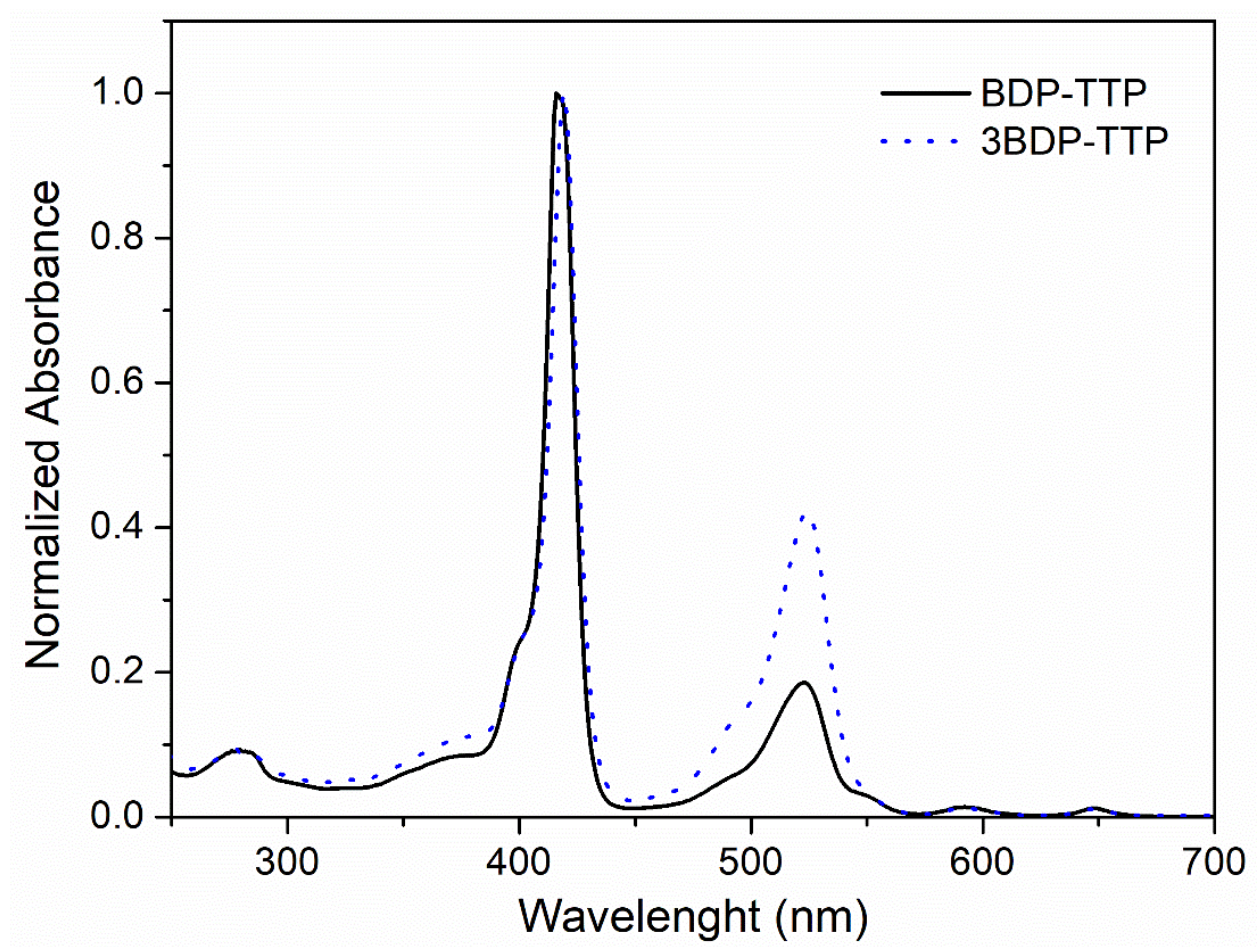

Figure 1. Steady-state absorption spectra of BDP-TTP and 3BDP-TTP compounds in THF $\left(2 \times 10^{-6} \mathrm{M}\right)$.

The emission spectra of the BODIPY-porphyrin compounds excited at $524 \mathrm{~nm}$ correspond to the BODIPY singlet state excitation, shown in Figure 2. The BODIPY control unit shows the intense emission at $542 \mathrm{~nm}$ (Figure S1). The BODIPY-porphyrin compounds exhibit emission around $544 \mathrm{~nm}$ from BODIPY and around $653 \mathrm{~nm}$ and $718 \mathrm{~nm}$ from the porphyrin by the excitation of the BODIPY unit at $524 \mathrm{~nm}$. BODIPY-based fluorescence is strongly quenched for BODIPY-porphyrin compounds compared to the fluorescence of the free BODIPY, provided in Figure S1. In addition, the excitation spectrum of BDP-TTP monitoring at $653 \mathrm{~nm}$, attributed to the fluorescence of porphyrin, shows a similar BODIPY absorption feature at $524 \mathrm{~nm}$, shown in Figure 3, and the other compound (3BDP-TTP) also shows similar results. Since the BODIPY absorption band is observed in the excitation spectra while monitoring the emission band of the porphyrin unit, it indicates the energy transfer from the BODIPY unit to porphyrin with the excitation of the BODIPY unit. The overlap of the fluorescence and absorption spectra are seen in Figure 4a,b for BDP-TTP and 3BDP-TTP, respectively. BODIPY-porphyrin compounds show Förster-type resonance energy transfer (FRET) from the BODIPY unit to porphyrin, due to the overlapping of the BODIPY emission spectrum and absorption of porphyrin Q-bands. To gain deeper 
insight of the energy transfer mechanism of the studied compounds, the pump-probe measurements were carried out.

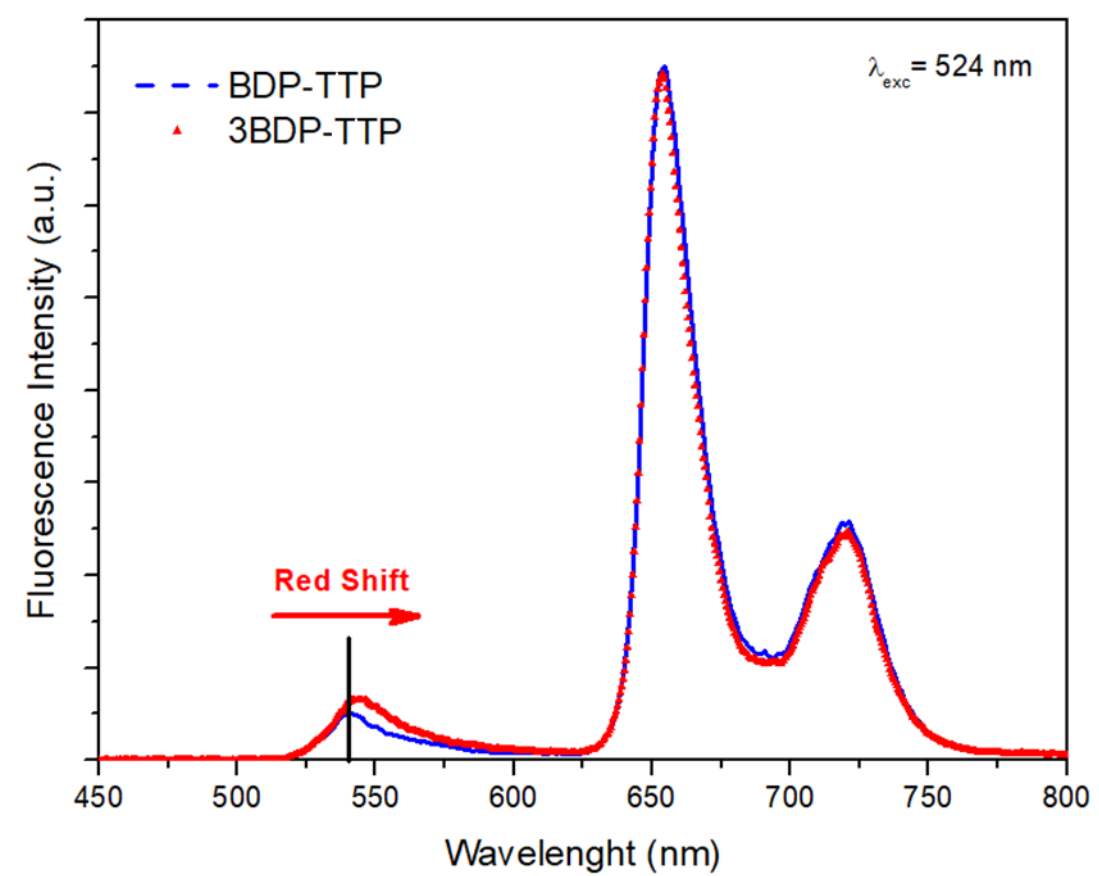

Figure 2. Emission spectra of BDP-TTP and 3BDP-TTP solutions in THF with the $524 \mathrm{~nm}$ excitation wavelength $\left(2 \times 10^{-6} \mathrm{M}\right)$.

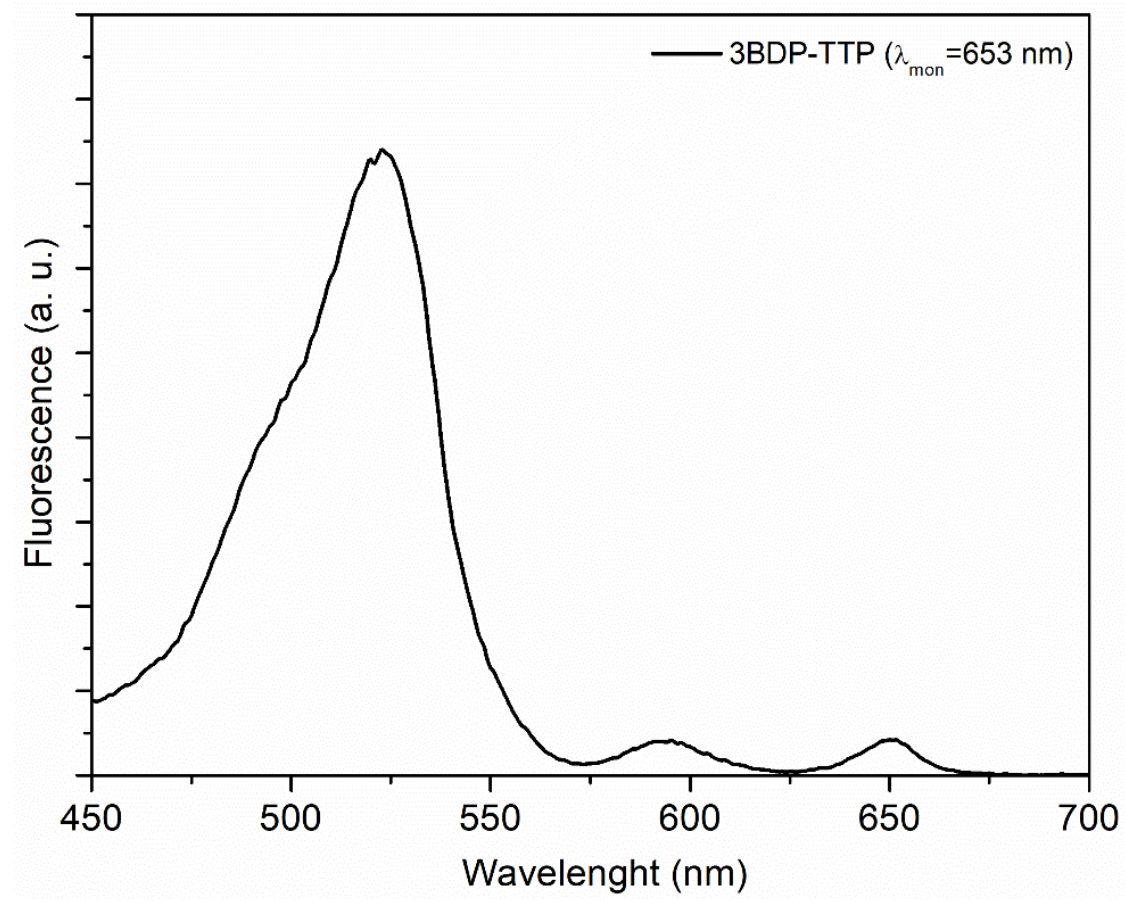

Figure 3. The excitation spectrum of 3BDP-TTP compound monitoring at the $653 \mathrm{~nm}$ wavelength. 


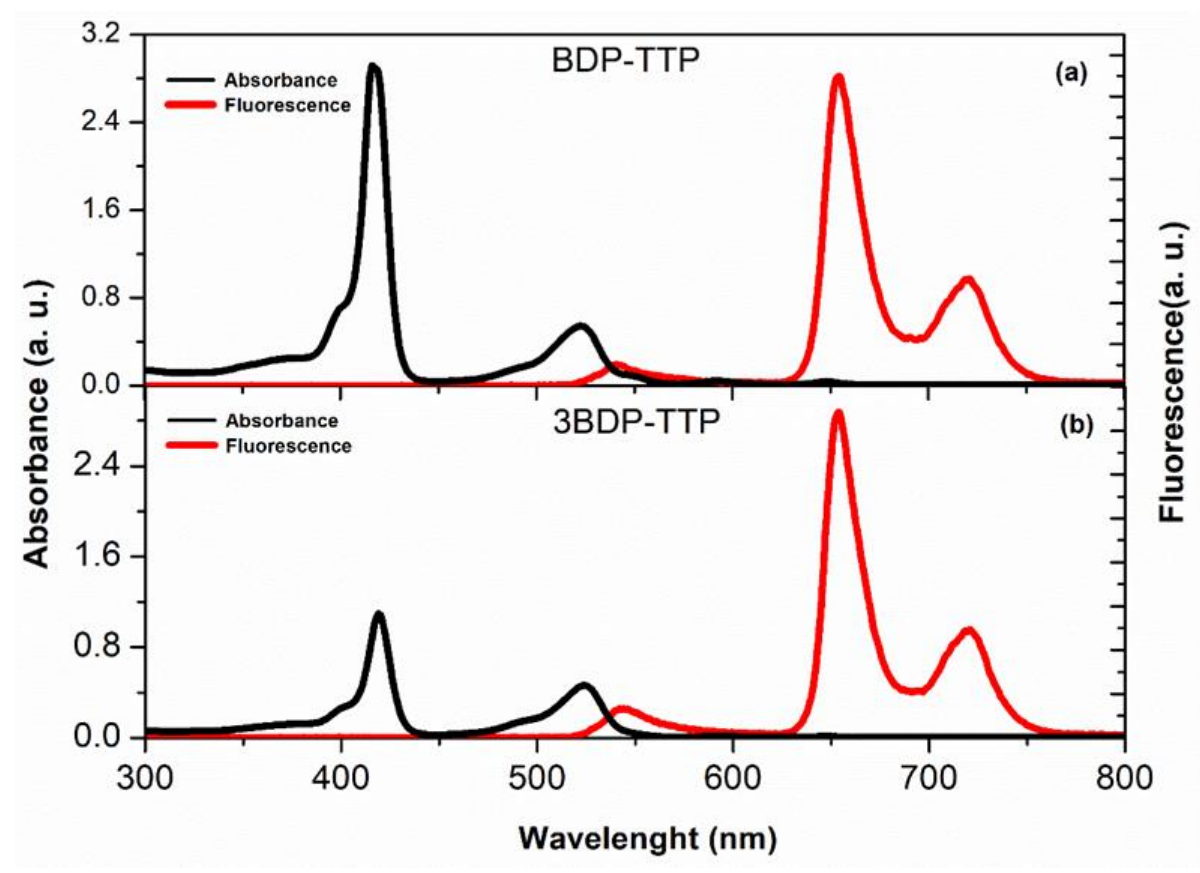

Figure 4. The overlap of the linear absorption and emission spectra of (a) BDP-TTP and (b) 3BDP-TTP with $524 \mathrm{~nm}$ excitation wavelengths.

\subsection{Ultrafast Pump-Probe Spectroscopy Measurements}

Ultrafast wavelength-dependent pump-probe spectroscopy measurements were carried out to investigate the excited state dynamics in BODIPY-porphyrin compounds and understand the energy transfer mechanism. In ultrafast pump-probe experiments, upon photoexcitation of BODIPY-porphyrin compounds, the energy transfer from BODIPY to porphyrin is observed via FRET mechanism [21]. Next, the excited state electron transfers to the triplet state of porphyrin by the intersystem-crossing mechanism. The porphyrinbased triplet-excited states are lower than the corresponding BODIPY-based triplet-excited state, so "back transfer" from the porphyrin to the BODIPY triplet is not possible in these cases. Thus, the porphyrin-based triplet-excited states can be readily generated by initial excitation of the BODIPY part of the dyads [52]. Therefore, in this paper, we consider that the triplet-triplet transition is more efficient in the porphyrin unit than in that of BODIPY, and the ESA around $450 \mathrm{~nm}$ was ascribed to triplet transitions of the Porphyrin unit. For this purpose, BODIPY-porphyrin compounds were probed with a $120 \mathrm{fs}$ white light continuum laser beam upon $400 \mathrm{~nm}$ and $524 \mathrm{~nm}$ pump excitation to excite porphyrin and BODIPY units, respectively.

Femtosecond transient absorption spectra for BDP-TTP and 3BDP-TTP are shown in Figures $5 \mathrm{a}$ and $6 \mathrm{a}$, respectively, with $524 \mathrm{~nm}$ pump wavelength. Transient absorption spectra of studied BODIPY-porphyrin compounds exhibited similar features, as compared to the literature [52,53]. As seen in these figures, the bleaching signal at the $524 \mathrm{~nm}$ has ascribed to the saturation of the singlet state of the BODIPY unit. The intensity of bleach signal of 3BDP-TTP is stronger than that of BDP-TTP, due to the higher energy transfer efficiency for 3BDP-TTP. The intensity of the bleaching signal of the BODIPY singlet-excited state is greatly diminished with the time delay as a result of the rapid energy transfer from the BODIPY-based singlet-excited state to singlet state of porphyrin. The decay traces of the bleaching signals were fitted by using a multiexponential function and probing 524 $\mathrm{nm}$ wavelength to obtain the energy transfer rates. The intramolecular energy transfer rates were obtained as $22 \mathrm{ps}$ for BDP-TTP and $3 \mathrm{ps}$ for 3BDP-TTP at the $524 \mathrm{~nm}$ probe wavelength, provided in Figures $5 b$ and $6 b$, respectively. The increase in the energy transfer rate from BODIPY to porphyrin is related to the energy difference between the singlet states of the BODIPY and porphyrin. The red shifting of the BODIPY emission spectrum in Figure 2 corresponds to the increasing of energy transfer rate in the BODIPY- 
porphyrin compound. Besides, the excited state absorption (ESA) signals of porphyrin rise simultaneously, while the intensity of the bleach signal around $524 \mathrm{~nm}$ that decreases over time (Figures $5 \mathrm{a}$ and $6 \mathrm{a}$ ). Similar to previous literature [21,54], the singlet-triplet transition (Intersystem crossing mechanism-ISC) of the porphyrin was observed for the studied BODIPY-porphyrin compounds after the fast singlet energy transfer from BODIPY to porphyrin. Further, the strong excited state absorption signal appeared around $450 \mathrm{~nm}$ which is attributed to the triplet-triplet transition of the porphyrin unit. Porphyrin is a well-studied molecule in terms of the tendency of the ISC, and the triplet-triplet absorption of porphyrin is very characteristic and well known in the literature. Our observation on the ESA from the triplet level of the porphyrin also supports the previous studies. On the other hand, ultrafast pump probe experiments were also performed for the tetratoly porphyrin compound, which was used as a reference compound, and 3BDP-TTP compound was used to confirm whether there is an energy transfer from the porphyrin unit to BODIPY core or not. The experimental results showed that the transient absorption spectra of the tetratolyl porphyrin compound exhibits similar transient absorption characteristic features as compared to the 3BDP-TTP compound by populating the singlet state of the porphyrin unit at $400 \mathrm{~nm}$ pump wavelength (Figures S2 and S3). Upon the photoexcitation of BODIPY-porphyrin compounds at $400 \mathrm{~nm}$, corresponding to the linear absorption band of porphyrin, only porphyrin-based transient absorption features were observed, while any BODIPY-based transient absorption property could not be seen. This result showed that there is no reverse energy transfer from the porphyrin to BODIPY unit, as seen in Figure S3.

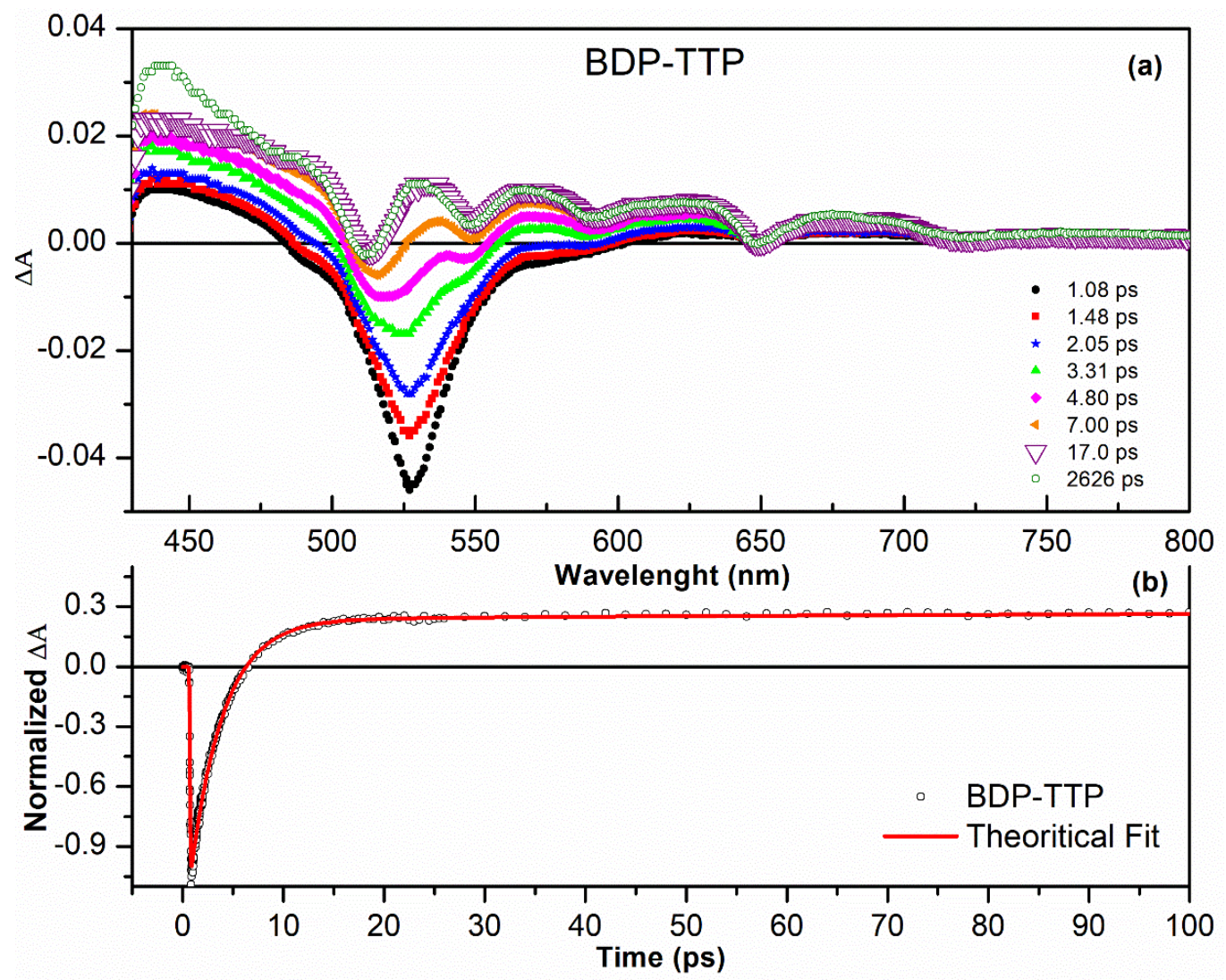

Figure 5. (a) The transient absorption spectra of BDP-TTP with different time delays. (b) Decay traces of the BDP-TTP at the $524 \mathrm{~nm}$ probe wavelength.

According to the literature [52], the energy transfer mechanism is attributed to the Förstertype energy transfer mechanism. The measured energy transfer rates from BODIPY to porphyrin are faster than in the literature [52], due to the spatial closeness of BODIPY and porphyrin molecules. In addition, energy transfer rates increase when increasing the number of BODIPY units, as seen in Figure 7. Therefore, increasing the number of BODIPY units provides not only 
an increasing absorption of the compound but also increases the energy transfer rate, due to slight energy level changes. The energy transfer diagram was given in Figure 8 .
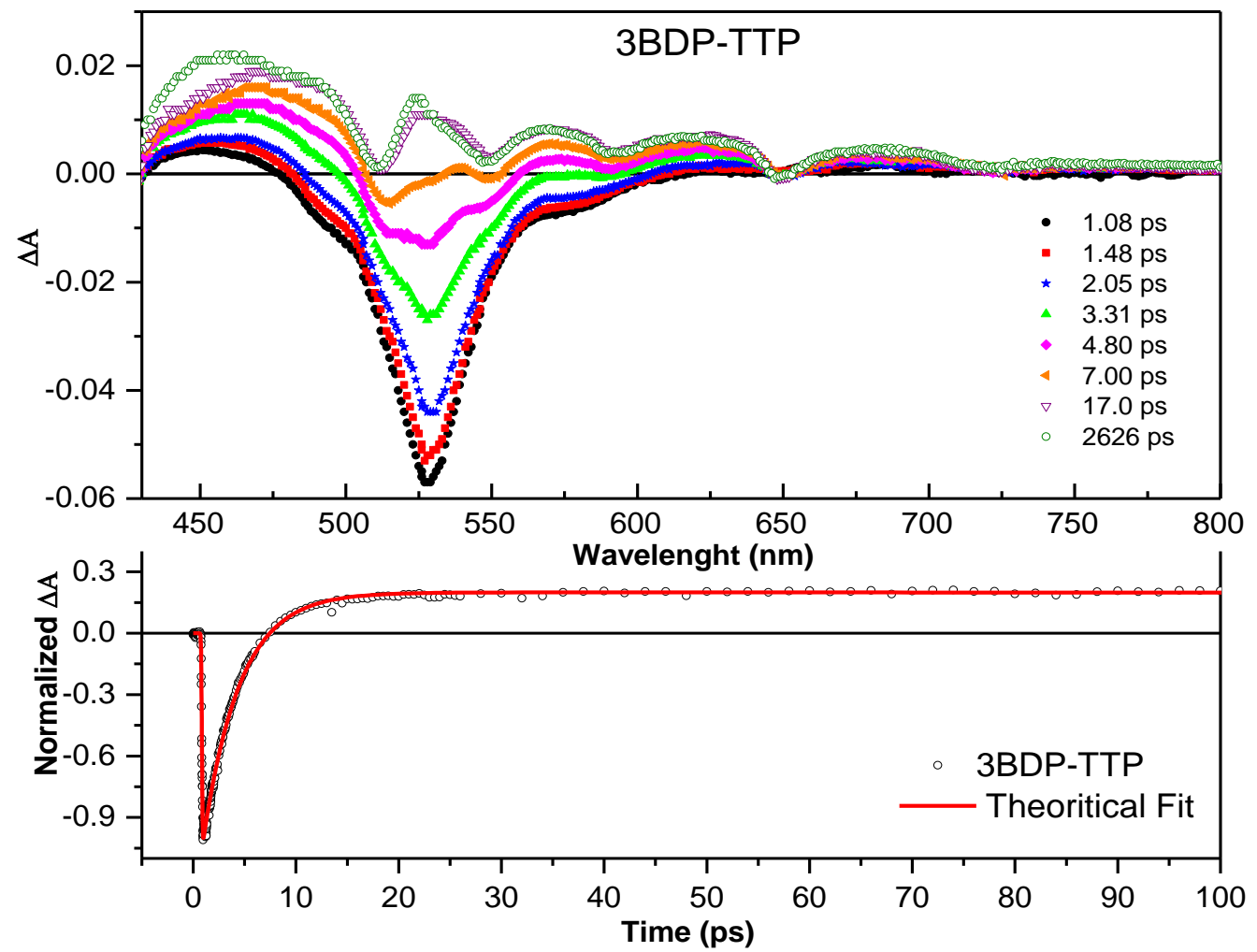

Figure 6. (top) The transient absorption spectra of 3BDP-TTP with different time delays. (bottom) Decay traces of 3BDP-TTP at the $524 \mathrm{~nm}$ probe wavelength.

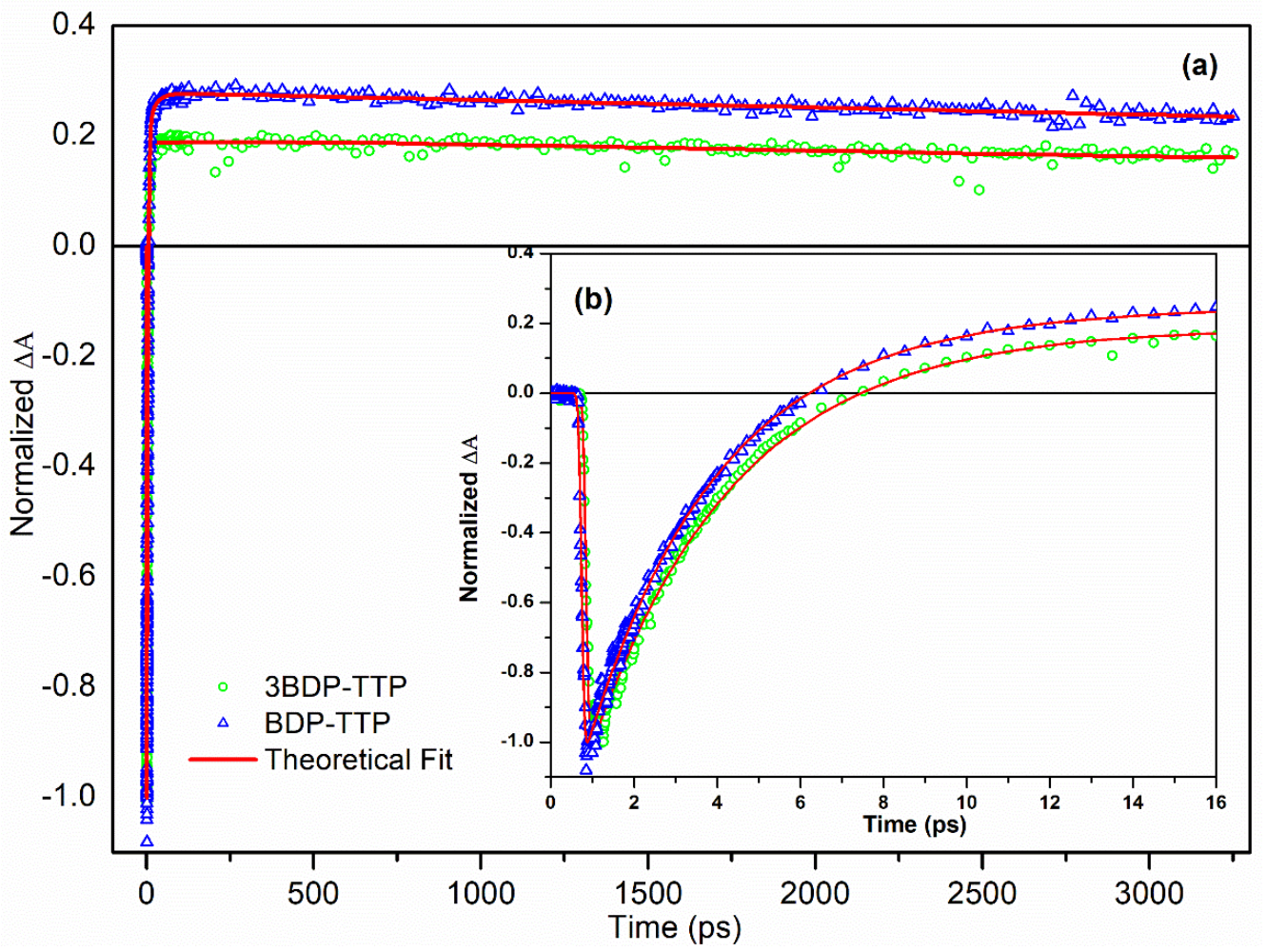

Figure 7. (a) Decay kinetics of BDP-TTP and 3BDP-TTP at $524 \mathrm{~nm}$ probe wavelength. (b) The inset represents zoomed decay traces between a 0 and 16 ps timescale. 


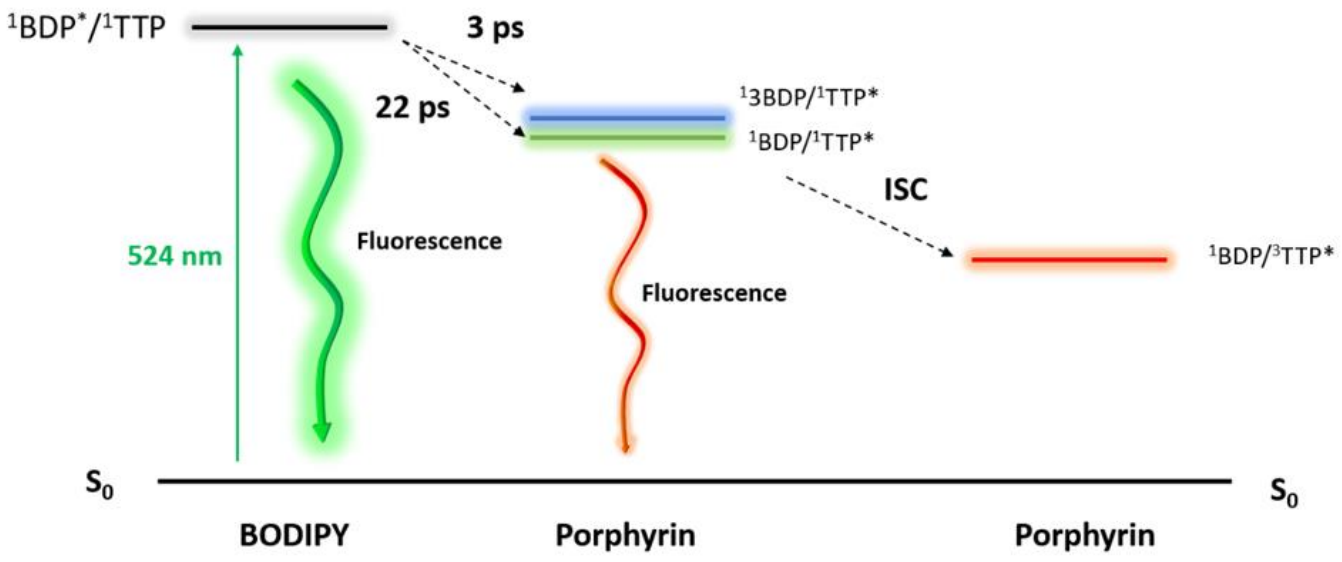

Figure 8. Energy level diagrams for BDP-TTP and 3BDP-TTP compounds.

\section{Conclusions}

In summary, we studied the energy transfer mechanism of the novel synthesized BODIPY-porphyrin compounds, including different numbers of BODIPY units, by performing steady-state absorption and emission spectroscopy and ultrafast pump-probe spectroscopy techniques. The fluorescence and excitation measurement results confirm that the energy transfer from the BODIPY unit to porphyrin occurs for the studied compounds and that energy transfer is also supported with ultrafast pump-probe spectroscopy results. There is a significant fluorescence quenching from the BODIPY unit which is strong evidence for the efficient energy transfer mechanism. Intermolecular energy transfer rates were obtained as $22 \mathrm{ps}$ for BDP-TTP and $3 \mathrm{ps}$ for 3BDP-TTP. The energy transfer rate increases with the increasing number of BODIPY units, due to the bigger overlapping on absorption and fluorescence spectra. Further, it has been proven that this energy transfer only happens in one direction (from BODIPY to porphyrin). These findings can lead to investigating the better antenna effect for the BODIPY-porphyrin compound with varying numbers of BODIPY units.

Supplementary Materials: The following are available online at https://www.mdpi.com/2227-971 7/9/2/312/s1.

Author Contributions: Conceptualization, B.K., A.K., M.H. and A.E.; data curation, Y.T. and E.A.Y.; investigation, Y.T., G.S., E.A.Y., F.M.D. and H.Y.; methodology, B.K., A.K., M.H. and A.E.; resources, G.S., F.M.D. and H.Y.; supervision, B.K. and A.K.; writing-original draft preparation, Y.T., G.S. and B.K.; writing-review and editing, E.A.Y., A.K., M.H. and A.E. All authors have read and agreed to the published version of the manuscript.

Funding: This research received no external funding.

Conflicts of Interest: The authors declare no conflict of interest.

\section{References}

1. Khan, T.K.; Ravikanth, M. Synthesis of covalently linked boron-dipyrromethene-chromophore conjugates using 3-bromo borondipyrromethene as a key precursor. Tetrahedron 2011, 67, 5816-5824. [CrossRef]

2. Ziessel, R.; Ulrich, G.; Harriman, A. The chemistry of Bodipy: A new El Dorado for fluorescence tools. N. J. Chem. 2007, 31, 496-501. [CrossRef]

3. Ulrich, G.; Ziessel, R.; Harriman, A. The chemistry of fluorescent bodipy dyes: Versatility unsurpassed. Angew. Chem. Int. Ed. 2008, 47, 1184-1201. [CrossRef]

4. Benstead, M.; Mehl, G.H.; Boyle, R.W. 4,4'-Difluoro-4-bora-3a,4a-diaza-s-indacenes (BODIPYs) as components of novel light active materials. Tetrahedron 2011, 67, 3573-3601. [CrossRef]

5. Loudet, A.; Burgess, K. BODIPY dyes and their derivatives: Syntheses and spectroscopic properties. Chem. Rev. 2007, 107, 4891-4932. [CrossRef]

6. Guliyev, R.; Coskun, A.; Akkaya, E.U. Design strategies for ratiometric chemosensors: Modulation of excitation energy transfer at the energy donor site. J. Am. Chem. Soc. 2009, 131, 9007-9013. [CrossRef] 
7. Sevinç, G.; Küçüköz, B.; Yilmaz, H.; Şirikçi, G.; Yaglioglu, H.G.; Hayvali, M.; Elmali, A. Explanation of pH probe mechanism in borondipyrromethene-benzimidazole compound using ultrafast spectroscopy technique. Sens. Actuators B Chem. 2014, 193, 737-744. [CrossRef]

8. Kobayashi, H.; Ogawa, M.; Alford, R.; Choyke, P.L.; Urano, Y. New Strategies for Fluorescent Probe Design in Medical Diagnostic Imaging. Chem. Rev. 2010, 110, 2620-2640. [CrossRef]

9. Lai, R.Y.; Bard, A.J. Electrogenerated chemiluminescence 71. Photophysical, electrochemical, and electrogenerated chemiluminescent properties of selected dipyrromethene-BF2 dyes. J. Phys. Chem. B 2003, 107, 5036-5042. [CrossRef]

10. Baruah, M.; Qin, W.; Basarić, N.; De Borggraeve, W.M.; Boens, N. BODIPY-based hydroxyaryl derivatives as fluorescent pH probes. J. Org. Chem. 2005, 70, 4152-4157. [CrossRef]

11. Rurack, K.; Kollmannsberger, M.; Daub, J. Molecular switching in the near infrared (NIR) with a functionalized borondipyrromethene dye. Angew. Chem. Int. Ed. 2001, 40, 385-387. [CrossRef]

12. Ziessel, R.; Bonardi, L.; Retailleau, P.; Ulrich, G. Isocyanate-, Isothiocyanate-, Urea-, and Thiourea-Substituted Boron Dipyrromethene Dyes as Fluorescent Probes. J. Org. Chem. 2006, 71, 3093-3102. [CrossRef]

13. Baruah, M.; Qin, W.; Vallée, R.A.L.; Beljonne, D.; Rohand, T.; Dehaen, W.; Boens, N. A highly potassium-selective ratiometric fluorescent indicator based on BODIPY azacrown ether excitable with visible light. Org. Lett. 2005, 7, 4377-4380. [CrossRef]

14. Turfan, B.; Akkaya, E.U. Modulation of boradiazaindacene emission by cation-mediated oxidative PET. Org. Lett. 2002, 4, 2857-2859. [CrossRef]

15. Li, F.; Yang, S.I.; Ciringh, Y.; Seth, J.; Martin, C.H.; Singh, D.L.; Kim, D.; Birge, R.R.; Bocian, D.F.; Holten, D.; et al. Design, synthesis, and photodynamics of light-harvesting arrays comprised of a porphyrin and one, two, or eight boron-dipyrrin accessory pigments. J. Am. Chem. Soc. 1998, 120, 10001-10017. [CrossRef]

16. Lammi, R.K.; Ambroise, A.; Balasubramanian, T.; Wagner, R.W.; Bocian, D.F.; Holten, D.; Lindsey, J.S. Structural control of photoinduced energy transfer between adjacent and distant sites in multiporphyrin arrays. J. Am. Chem. Soc. 2000, 122, 7579-7591. [CrossRef]

17. Ambroise, A.; Kirmaier, C.; Wagner, R.W.; Loewe, R.S.; Bocian, D.F.; Holten, D.; Lindsey, J.S. Weakly coupled molecular photonic wires: Synthesis and excited-state energy-transfer dynamics. J. Org. Chem. 2002, 67, 3811-3826. [CrossRef]

18. Zhong, F.; Karatay, A.; Zhao, L.; Zhao, J.; He, C.; Zhang, C.; Yaglioglu, H.G.; Elmali, A.; Küçüköz, B.; Hayvali, M. Broad-Band $\mathrm{N} \wedge \mathrm{N}$ Pt(II) Bisacetylide Visible Light Harvesting Complex with Heteroleptic Bodipy Acetylide Ligands. Inorg. Chem. 2015, 54, 7803-7817. [CrossRef]

19. Golovkova, T.A.; Kozlov, D.V.; Neckers, D.C. Synthesis and properties of novel fluorescent switches. J. Org. Chem. 2005, 70, 5545-5549. [CrossRef]

20. Guo, S.; Xu, L.; Xu, K.; Zhao, J.; Küçüköz, B.; Karatay, A.; Yaglioglu, H.G.; Hayvali, M.; Elmali, A. Bodipy-C60 triple hydrogen bonding assemblies as heavy atom-free triplet photosensitizers: Preparation and study of the singlet/triplet energy transfer. Chem. Sci. 2015, 6, 3724-3737. [CrossRef] [PubMed]

21. Dumanoğulları, F.M.; Tutel, Y.; Küçüköz, B.; Sevinç, G.; Karatay, A.; Yılmaz, H.; Hayvali, M.; Elmali, A. Investigation of ultrafast energy transfer mechanism in BODIPY-Porphyrin dyad system. J. Photochem. Photobiol. A Chem. 2019, 373, 116-121. [CrossRef]

22. Kumaresan, D.; Gupta, I.; Ravikanth, M. Synthesis of 21-oxoporphyrin building blocks and energy donor appended systems. Tetrahedron Lett. 2001, 42, 8547-8550. [CrossRef]

23. Wagner, R.W.; Lindsey, J.S. A molecular photonic wire. J. Am. Chem. Soc. 1994, 116, 9759-9760. [CrossRef]

24. Goeb, S.; Ziessel, R. Synthesis of novel tetrachromophoric cascade-type Bodipy dyes. Tetrahedron Lett. 2008, 49, 2569-2574. [CrossRef]

25. Ma, J.; Yuan, X.; Küçüköz, B.; Li, S.; Zhang, C.; Majumdar, P.; Karatay, A.; Li, X.; Gul Yaglioglu, H.; Elmali, A.; et al. Resonance energy transfer-enhanced rhodamine-styryl Bodipy dyad triplet photosensitizers. J. Mater. Chem. C 2014, 2, 3900-3913. [CrossRef]

26. Kim, T.G.; Castro, J.C.; Loudet, A.; Jiao, J.G.S.; Hochstrasser, R.M.; Burgess, K.; Topp, M.R. Correlations of structure and rates of energy transfer for through-bond energy-transfer cassettes. J. Phys. Chem. A 2006, 110, 20-27. [CrossRef]

27. Wan, C.W.; Burghart, A.; Chen, J.; Bergström, F.; Johansson, L.B.; Wolford, M.F.; Kim, T.G.; Topp, M.R.; Hochstrasser, R.M.; Burgess, K. Anthracene-BODIPY cassettes: Syntheses and energy transfer. Chem. A Eur. J. 2003, 9, 4430-4441. [CrossRef] [PubMed]

28. Hou, Y.; Kurganskii, I.; Elmali, A.; Zhang, H.; Gao, Y.; Lv, L.; Zhao, J.; Karatay, A.; Luo, L.; Fedin, M. Electronic coupling and spin-orbit charge transfer intersystem crossing (SOCT-ISC) in compact BDP-carbazole dyads with different mutual orientations of the electron donor and acceptor. J. Chem. Phys. 2020, 152. [CrossRef] [PubMed]

29. Xiaolin, Z.; Yi, X.; Xuhong, Q. Highly efficient energy transfer in the light harvesting system composed of three kinds of boron-dipyrromethene derivatives. Org. Lett. 2008, 10, 29-32. [CrossRef]

30. Bröring, M.; Krüger, R.; Link, S.; Kleeberg, C.; Köhler, S.; Xie, X.; Ventura, B.; Flamigni, L. Bis(BF2)-2,2'-bidipyrrins (BisBODIPYs): Highly fluorescent BODIPY dimers with large stokes shifts. Chem. A Eur. J. 2008, 14, 2976-2983. [CrossRef] [PubMed]

31. Benniston, A.C.; Copley, G.; Elliott, K.J.; Harrington, R.W.; Clegg, W. Redox-controlled fluorescence modulation in a BODIPYquinone dyad. Eur. J. Org. Chem. 2008, 2705-2713. [CrossRef]

32. Bura, T.; Retailleau, P.; Ziessel, R. Efficient synthesis of panchromatic dyes for energy concentration. Angew. Chem. Int. Ed. 2010, 49, 6659-6663. [CrossRef] 
33. Wang, Z.; Zhao, J.; Barbon, A.; Toffoletti, A.; Liu, Y.; An, Y.; Xu, L.; Karatay, A.; Yaglioglu, H.G.; Yildiz, E.A.; et al. Radical-Enhanced Intersystem Crossing in New Bodipy Derivatives and Application for Efficient Triplet-Triplet Annihilation Upconversion. J. Am. Chem. Soc. 2017, 139, 7831-7842. [CrossRef] [PubMed]

34. Guo, S.; Ma, L.; Zhao, J.; Küçüköz, B.; Karatay, A.; Hayvali, M.; Yaglioglu, H.G.; Elmali, A. BODIPY triads triplet photosensitizers enhanced with intramolecular resonance energy transfer (RET): Broadband visible light absorption and application in photooxidation. Chem. Sci. 2014, 5, 489-500. [CrossRef]

35. Ghosh, A.; Vangberg, T. Comparative Thermochemistry of Metalloporphyrin Isomers as a Function of Metal Ion Size. A Possible Insight into Nature's Choice of Porphyrin over Isomeric Ligands. Inorg. Chem. 1998, 37, 6276-6280. [CrossRef]

36. Sisemore, M.F.; Selke, M.; Burstyn, J.N.; Valentine, J.S. Metalloporphyrin Peroxo Complexes of Iron(III), Manganese(III), and Titanium(IV). Comparative Studies Demonstrating That the Iron(III) Complex Is Extremely Nucleophilic. Inorg. Chem. 1997, 36, 979-984. [CrossRef] [PubMed]

37. Pan, L.; Huang, X.; Phan, H.L.N.; Emge, T.J.; Li, J.; Wang, X. 1-D infinite array of metalloporphyrin cages. Inorg. Chem. 2004, 43, 6878-6880. [CrossRef]

38. Giribabu, L.; Rao, T.A.; Maiya, B.G. “Axial-bonding"-type hybrid porphyrin arrays: Synthesis, spectroscopy, electrochemistry, and singlet state properties. Inorg. Chem. 1999, 38, 4971-4980. [CrossRef]

39. Burrell, A.K.; Officer, D.L.; Plieger, P.G.; Reid, D.C.W. Synthetic routes to multiporphyrin arrays. Chem. Rev. 2001, 101, 2751-2796. [CrossRef]

40. Nakamura, Y.; Hwang, I.W.; Aratani, N.; Ahn, T.K.; Ko, D.M.; Takagi, A.; Kawai, T.; Matsumoto, T.; Kim, D.; Osuka, A. Directly meso-meso linked porphyrin rings: Synthesis, characterization, and efficient excitation energy hopping. J. Am. Chem. Soc. 2005, 127, 236-246. [CrossRef]

41. Kodis, G.; Liddell, P.A.; De la Garza, L.; Clausen, P.C.; Lindsey, J.S.; Moore, A.L.; Moore, T.A.; Gust, D. Efficient energy transfer and electron transfer in an artificial photosynthetic antenna-reaction center complex. J. Phys. Chem. A 2002, 106, 2036-2048. [CrossRef]

42. Terazono, Y.; Kodis, G.; Bhushan, K.; Zaks, J.; Madden, C.; Moore, A.L.; Moore, T.A.; Fleming, G.R.; Gust, D. Mimicking the role of the antenna in photosynthetic photoprotection. J. Am. Chem. Soc. 2011, 133, 2916-2922. [CrossRef]

43. Aratani, N.; Osuka, A.; Kim, Y.H.; Jeong, D.H.; Kim, D. Extremely long, discrete meso-meso-coupled porphyrin arrays. Angew. Chem. Int. Ed. 2000, 39, 1458-1462. [CrossRef]

44. Gust, D.; Moore, T.A.; Moore, A.L. Solar fuels via artificial photosynthesis. Acc. Chem. Res. 2009, 42, 1890-1898. [CrossRef]

45. Holten, D.; Bocian, D.F.; Lindsey, J.S. Probing electronic communication in covalently linked multiporphyrin arrays. A guide to the rational design of molecular photonic devices. Acc. Chem. Res. 2002, 35, 57-69. [CrossRef]

46. Uetomo, A.; Kozaki, M.; Suzuki, S.; Yamanaka, K.I.; Ito, O.; Okada, K. Efficient light-harvesting antenna with a multi-porphyrin cascade. J. Am. Chem. Soc. 2011, 133, 13276-13279. [CrossRef]

47. Karam, T.E.; Siraj, N.; Ranasinghe, J.C.; Kolic, P.E.; Regmi, B.P.; Warner, I.M.; Haber, L.H. Efficient Photoinduced Energy Transfer in Porphyrin-Based Nanomaterials. J. Phys. Chem. C 2020. [CrossRef]

48. Seo, C.; Kim, M.; Lee, J.; Lee, C.Y.; Kim, J. Spectroscopic evidence of energy transfer in bodipy-incorporated nano-porphyrinic metal-organic frameworks. Nanomaterials 2020, 10, 1925. [CrossRef] [PubMed]

49. Obondi, C.O.; Lim, G.N.; Martinez, P.; Swamy, V.; D’Souza, F. Controlling electron and energy transfer paths by selective excitation in a zinc porphyrin-BODIPY-C60 multi-modular triad. Nanoscale 2017, 9, 18054-18065. [CrossRef]

50. Qin, W.; Baruah, M.; Stefan, A.; Van Der Auweraer, M.; Boens, N. Photophysical properties of BODIPY-derived hydroxyaryl fluorescent $\mathrm{pH}$ probes in solution. ChemPhysChem 2005, 6, 2343-2351. [CrossRef]

51. López Arbeloa, F.; Bañuelos, J.; Martínez, V.; Arbeloa, T.; López Arbeloa, I. Structural, photophysical and lasing properties of pyrromethene dyes. Int. Rev. Phys. Chem. 2005, 24, 339-374. [CrossRef]

52. Lazarides, T.; Charalambidis, G.; Vuillamy, A.; Réglier, M.; Klontzas, E.; Froudakis, G.; Kuhri, S.; Guldi, D.M.; Coutsolelos, A.G. Promising fast energy transfer system via an easy synthesis: Bodipy-porphyrin dyads connected via a cyanuric chloride bridge, their synthesis, and electrochemical and photophysical investigations. Inorg. Chem. 2011, 50, 8926-8936. [CrossRef]

53. Hu, Q.Q.; Zhu, Y.Z.; Zhang, S.C.; Tong, Y.Z.; Zheng, J.Y. Meso-2'-Linked porphyrin-BODIPY hybrids: Synthesis and efficient excitation energy transfer. Dalt. Trans. 2015, 44, 15523-15530. [CrossRef]

54. Whited, M.T.; Djurovich, P.I.; Roberts, S.T.; Durrell, A.C.; Schlenker, C.W.; Bradforth, S.E.; Thompson, M.E. Singlet and triplet excitation management in a bichromophoric near-infrared-phosphorescent BODIPY-benzoporphyrin platinum complex. J. Am. Chem. Soc. 2011, 133, 88-96. [CrossRef] 